\title{
Non-invasive ventilation in the treatment of early hypoxemic respiratory failure caused by COVID-19: considering nasal CPAP as the first choice
}

\author{
Lili Guan $^{1+}$ (D), Luqian Zhou ${ }^{1 \dagger}$, Jehane Michael Le Grange ${ }^{2 \dagger}$, Zeguang Zheng ${ }^{1+}$ and Rongchang Chen ${ }^{3^{*}}$
}

High-flow nasal oxygen (HFNO) and non-invasive ventilation (NIV) have been used to manage early acute hypoxemic respiratory failure (AHRF) caused by COVID-19. As there is no evidence-based recommendation for the selection of HFNO or NIV, staff tend to base their choice on personal preference (Fig. 1).

Frat et al. [1] showed that HFNO was associated with lower 90-day mortality in AHRF patients, which had a strong impact on clinical practice. However, there are some limitations in methodology. Firstly, NIV median daily usage was only $8 \mathrm{~h}$. Furthermore, high expiratory tidal volume $(9.2 \pm 3.0 \mathrm{~mL} / \mathrm{kg})$ and low PEEP $\left(5 \mathrm{cmH}_{2} \mathrm{O}\right)$ may have negative impact on the efficacy of NIV. When considering therapeutic mechanisms, adjustable airway pressure, oxygen consumption, and patient tolerance, nasal continuous positive airway pressure (nCPAP) seems to have advantages and should be considered as the first choice.

As for therapeutic mechanism, HFNO is supposed to generate low PEEP $\left(3 \mathrm{cmH}_{2} \mathrm{O}\right.$ on average). However, this pressure level is unstable, uncontrollable, and affected by many factors [2]. In contrast, nCPAP can provide stable and adjustable airway pressure.

When considering constant, high fraction of inspired oxygen $\left(\mathrm{FiO}_{2}\right)$ and oxygen consumption, HFNO has the

\footnotetext{
*Correspondence: chenrc@vip.163.com

'Lili Guan, Luqian Zhou, Jehane Michael Le Grange and Zeguang Zheng contributed equally to this work.

${ }^{3}$ Department of Respiratory and Critical Care Medicine, First Affiliated

Hospital of Southern University of Science and Technology, Second Clinical Medical College of Jinan University, Shenzhen People's Hospital, Shenzhen Institute of Respiratory Diseases, 1017 Dong Men Road, Shenzhen 518020, China

Full list of author information is available at the end of the article
}

advantage of providing stable $\mathrm{FiO}_{2}$. However, it consumes large amounts of oxygen. When $\mathrm{FiO}_{2}$ is set to be $50 \%$ and flow to be $50 \mathrm{~L} / \mathrm{min}, 18.4 \mathrm{~L} / \mathrm{min}$ of $100 \%$ oxygen will be consumed. With nCPAP, a mean of $50 \%$ $\mathrm{FiO}_{2}$ can be achieved with $5-6 \mathrm{~L} / \mathrm{min}$ of $100 \%$ oxygen delivered directly into the mask. Given current resource limitations, oxygen supply should be an important consideration as patients requiring oxygen increases dramatically.

Patient tolerance when continuously using HFNO or NIV is another consideration, as continuous positive airway pressure without interruption seems important during AHRF, especially early ARDS [3]. HFNO has particular advantage in tolerance. However, nCPAP remains well-tolerated with no patient-ventilator asynchrony.

With regard to concerns that nCPAP may increase risk of transmission, evidence remains controversial. Recent study stated that exhaled air dispersion would also increase during HNFO, theoretically making it no better than nCPAP [4]. In Guangdong, China, no healthcare workers were infected during NIV management under the Chinese guidance of personal protection [5].

In conclusion, there remains paucity evidence on how to choose between HFNO and nCPAP treating mild AHRF due to COVID-19. Theoretically, nCPAP has more advantages. Prospective randomized controlled trials are necessary to compare HFNO with nCPAP to provide more evidence on the indications for different noninvasive respiratory support and also indications for selecting between NIV and intubation. 


\begin{tabular}{|c|c|c|c|c|c|}
\hline & Published date & Journal & Country & NIV & HFNO \\
\hline Arentz et.al & April, 2020 & JAMA & United States & $4(19)$ & $1(5)$ \\
\hline Grasselli et.al & April, 2020 & JAMA & Italy & $137(11)$ & N.A. \\
\hline Myers et.al & April, 2020 & JAMA & United States & $1(1)$ & $4(4)$ \\
\hline Piva et.al & April, 2020 & $\begin{array}{c}\text { Journal of } \\
\text { Critical Care }\end{array}$ & Italy & $13(39)$ & N.A. \\
\hline Wang et.al & February, 2020 & JAMA & China & $15(42)$ & $4(11)$ \\
\hline Yang et.al & February, 2020 & Lancet & China & $29(56)$ & $33(64)$ \\
\hline Yu et.al & May, 2020 & $\begin{array}{c}\text { Critical Care } \\
\text { Journal of }\end{array}$ & China & $20(9)$ & $37(16)$ \\
\hline Zheng et.al & May, 2020 & $\begin{array}{l}\text { Zhejiang } \\
\text { University }\end{array}$ & China & N.A. & $18(53)$ \\
\hline
\end{tabular}

Fig. 1 Proportion of patients with COVID-19 receiving NIV or HFNO in ICU among different studies. Data are $n$ (\%). COVID-19, coronavirus disease 2019; NIV, non-invasive ventilation; HFNO, high flow nasal oxygen; ICU, intensive care unit, N.A., not applicable

\begin{abstract}
Abbreviations
HFNO: High-flow nasal oxygen; NIV: Non-invasive ventilation; AHRF: Acute hypoxemic respiratory failure; COVID-19: Coronavirus disease 2019; nCPAP: Nasal continuous positive airway pressure; $\mathrm{FiO}_{2}$ : Fraction of inspired oxygen
\end{abstract}

\section{Acknowledgements}

Not applicable.

\section{Authors' contributions}

R.C. Chen and L.Q. Zhou contributed to determining the outline and content of the correspondence. L.L. Guan, J.M. Le Grange, and Z.G. Zheng contributed to retrieving literature and writing a draft of this manuscript. All authors contributed to revising the draft critically for important intellectual content, providing final confirmation of the revised version, and being responsible for all aspects of the work. The authors read and approved the final manuscript.

\section{Authors' information}

Rongchang Chen, MD, MS, FCCP, Prof; director of the Shenzhen Institute of Respiratory Diseases, Shenzhen People's Hospital; former director of the Guangzhou Institute of Respiratory Health; the 10th president of the Chinese Thoracic Society; the 1st president of Assembly of Respiratory Disease, Chinese Association of Medical Equipment; deputy director of National Clinical Research Center for Respiratory Disease and one of the GOLD Board of Directors.

\section{Funding}

Not applicable.

\section{Availability of data and materials \\ Not applicable.}

Ethics approval and consent to participate

Not applicable.

\section{Consent for publication}

Not applicable.

\section{Author details}

${ }^{1}$ State Key Laboratory of Respiratory Disease, National Clinical Research Center for Respiratory Disease, Guangzhou Institute of Respiratory Health, The First Affiliated Hospital of Guangzhou Medical University, Guangzhou, Guangdong, China. '2Department of Emergency Medicine, Union Hospital, Tongji Medical College, Huazhong University of Science and Technology, Wuhan, Hubei, China. ${ }^{3}$ Department of Respiratory and Critical Care Medicine, First Affiliated Hospital of Southern University of Science and Technology, Second Clinical Medical College of Jinan University, Shenzhen People's Hospital, Shenzhen Institute of Respiratory Diseases, 1017 Dong Men Road, Shenzhen 518020, China.

Received: 26 May 2020 Accepted: 2 June 2020

Published online: 11 June 2020

\section{References}

1. Frat JP, Thille AW, Mercat A, Girault C, Ragot S, Perbet S, Prat G, Boulain T, Morawiec E, Cottereau A, et al. High-flow oxygen through nasal cannula in acute hypoxemic respiratory failure. N Engl J Med. 2015;372(23):2185-96.

2. Parke RL, Eccleston ML, McGuinness SP. The effects of flow on airway pressure during nasal high-flow oxygen therapy. Respir Care. 2011;56(8): 1151-5.

3. Ferrer M, Esquinas A, Leon M, Gonzalez G, Alarcon A, Torres A. Noninvasive ventilation in severe hypoxemic respiratory failure: a randomized clinical trial. Am J Respir Crit Care Med. 2003;168(12):1438-44.

4. Leonard S, Atwood CW Jr, Walsh BK, DeBellis RJ, Dungan GC, Strasser W, Whittle JS. Preliminary findings on control of dispersion of aerosols and droplets during high-velocity nasal insufflation therapy using a simple surgical mask: implications for the high-flow nasal cannula. Chest. 2020. https://doi.org/10.1016/j.chest.2020.03.043.

5. Respiratory Care Committee of Chinese Thoracic S. Expert consensus on preventing nosocomial transmission during respiratory care for critically ill patients infected by 2019 novel coronavirus pneumonia. Zhonghua jie he he hu xi za zhi. 2020;43(4):288-96.

\section{Publisher's Note}

Springer Nature remains neutral with regard to jurisdictional claims in published maps and institutional affiliations. 